\title{
Влияние новейшей тектоники на гидротехнические сооружения Кемского каскада ГЭС
}

\author{
Авдонина А.М. ${ }^{1}$, Бондарь И.В. ${ }^{2}$ \\ ${ }^{1}$ Московский государственный университет им. М.В. Ломоносова, Москва, ukeltik@bk.ru \\ ${ }^{2}$ Институт физики Земли им. О.Ю. Шмидта РАН, Москва, bond@ifz.ru
}

\begin{abstract}
Аннотация. На территории Карелии расположено большое количество гидроэлектростанций (ГЭС) на которых вырабатывается около 70 \% производимой в республике электроэнергии. Сама территория Карелии обладает большим ресурсным потенциалом по энергоснабжению, так как Республика входит в число 14 субъектов Российской Федерации, занимающих лидирующие позиции по водообеспеченности территории. Наиболее мощные ГЭС стоят на реке Кемь. Несмотря на равнинную, болотистую местность территория Карелии характеризуется интенсивными новейшими тектоническими движениями, которые могут представлять опасность для гидротехнических сооружений. По результатам исследования выяснено, что почти все ГЭС расположены в пределах сейсмоактивной неотектонической структуры - Кемско-Топозерского прогиба. Вдоль этого прогиба зафиксированы множественные сейсмические события с магнитудой от 1 до 4.
\end{abstract}

Ключевые слова: Кемский каскад ГЭС, гидро-электростанции, Северная Карелия, новейшая тектоника, структурно-геоморфологический метод, новейшие структуры, сейсмичность.

\section{The influence of the recent tectonics on the hydro-technical utilities of the Kem' cascade of hydroelectric power plants}

\author{
Avdonina A.M. ${ }^{1}$, Bondar I.V. ${ }^{2}$ \\ ${ }^{1}$ Lomonosov Moscow State University, Moscow, ukeltik@bk.ru \\ ${ }^{2}$ Schmidt institute of physics of the earth of the RAS, Moscow, bond@ifz.ru
}

\begin{abstract}
On the area of Karelia there are a large number of hydroelectric power plants (HPPs) that generate about $70 \%$ of the electricity produced in the Republic. The territory of Karelia itself has a great resource potential for energy supply, as the Republic is among the 14 subjects of the Russian Federation that occupy leading positions in terms of water supply of the territory. The most powerful hydroelectric power stations are located on the Kem' River. Despite the flat, swampy terrain, the territory of Karelia is characterized by intensive recent tectonic movements that can pose a danger to hydro-technical utilities. According to the results of the study, it was found that almost all hydroelectric power plants are located within the seismically active neotectonic structure - the Kemsko-Topozersky trough. Multiple seismic events with magnitudes ranging from 1 to 4 were recorded along this trough.

Key words: Kem' cascade HPPs, hydroelectric power plants, North Karelia, the recent tectonics, structural and geomorphological method, the recent structures, seismicity.
\end{abstract}

\section{Введение}

В настоящее время ведется активное развитие Арктических регионов страны, создаются новые проекты в сторону экономического и инфраструктурного улучшения этой зоны (АЗРФ), и Карелия, входящая в её состав северными районами, обладает для этого большим ресурсным потенциалом. Республика входит в число 14 субъектов Российской Федерации, занимающих лидирующие

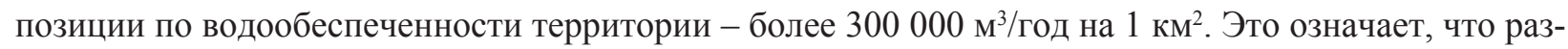
витие республики возможно при условии правильного использования такого огромного запаса водных ресурсов.

По СТО 17230282.27.140.022-2008 «Здания ГЭС и ГАЭС. Условия создания. Нормы и требования» ГЭС - это комплекс гидротехнических сооружений и оборудования, для преобразования потенциальной энергии водотока в электрическую энергию. В Карелии расположено 17 (со строящимися Белопорожскими ГЭС-1 и ГЭС-2 в 2020 г.) ГЭС суммарной мощностью 634 МВт, на которых вырабатывается около 70 \% производимой в республике электроэнергии. Наиболее мощные стоят 


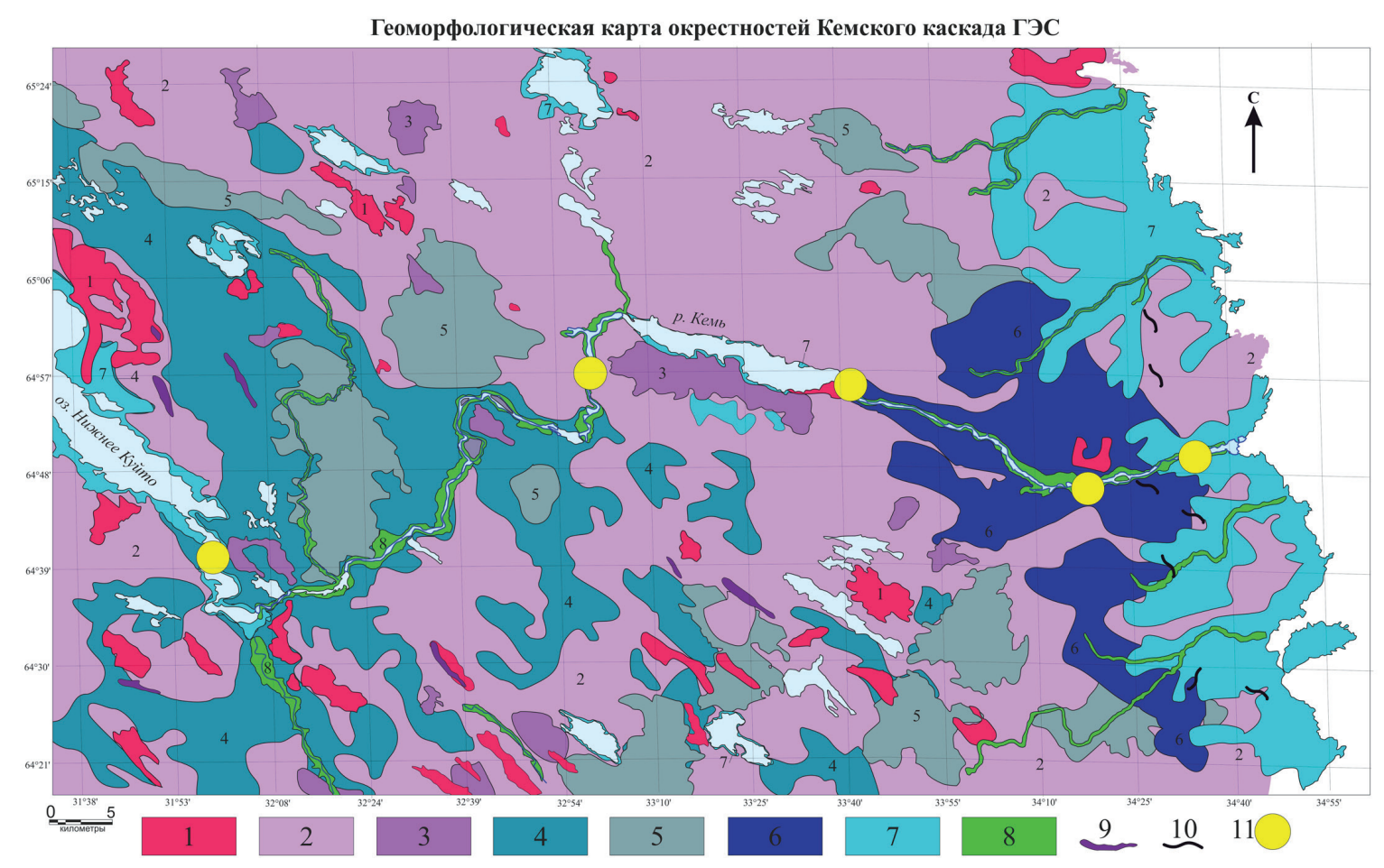

Рис. 1. Геоморфологическая карта окрестностей Кемского каскада ГЭС. Структурно-денудационный рельеф с экзарационной обработкой на кристаллическом фундаменте архейского и протерозойского возраста: 1 - крупно- и среднегрядовые равнины. Ледниковый рельеф позднеплейстоценового возраста: 2 - холмистозападинные моренные равнины, 3 - грядово-холмистые моренные равнины. Водно-ледниковый рельеф позднеплейстоценового возраста: 4 - слабоволнистые озерно-ледниковые равнины, 5 - плоские озерноледниковые равнины, 9 - озы. Озерный и морской рельеф: 6 - плиоцен-плейстоценовые; 7 - плоские равнины голоценовые, 10 - береговые валы. Флювиальный рельеф: 8 - речные долины со слабовыраженными пойменными уровнями и НПТ (или их отсутствием). Прочее: $11-$ ГЭС.

Fig. 1. Geomorphological map of the vicinity of the Kem' cascade of hydroelectric power plants. Structural-denudation relief with exaration treatment on the crystal basement of Archean and Proterozoic age: 1 - large and mediumrange plains. Glacial relief of Late Pleistocene age: 2 - hilly-westerly moraine plains, 3-ridge-hilly moraine plains. Water-glacial relief of Late Pleistocene age: 4 - slightly undulating lake-glacial plains, 5 - flat lake-glacial plains, 9 - asar. Lake and sea topography: 6 - Pliocene-Pleistocene; 7 - Holocene flat plains, 10 - coastal ramparts. Fluvial relief: 8 - river valleys with weak floodplain levels and NPTs (or their absence). Other: $11-$ HPP.

на реке Кемь. Кемский каскад включает в себя (далее по мере снижения мощности): Кривопорожскую, Путкинскую, Подужемскую, Юшкозерскую ГЭС и строящийся Белопорожский каскад.

Несмотря на равнинную, болотистую местность, территория Карелии характеризуется интенсивными новейшими движениями, которые могут представлять опасность для гидротехнических сооружений. В данной работе изучаются новейшие тектонические структуры Северной Карелии и их влияние на ГЭС Кемского каскада.

\section{Методика исследования}

Исследования проводились с помощью структурно-геоморфологического метода Макаровой Н.В. (Макарова, Суханова, 2015). В основе данного метода лежит представление о том, что рельеф в новейшее время развивается стадийно. Стадия пенепленизации и практически полного выравнивания рельефа сменяется стадией поднятия. Вследствие поднятия понижается базис эрозии и пенеплен эродирует, образуя останцовые поверхности выравнивания. Возраст самой древней поверхности выравнивания в каком-либо районе указывает на время начала поднятия, а количество поверхностей выравнивания - на интенсивность поднятия. За основу была взята топографическая карта 
масштаба 1:1 000000 Q-35. Также были привлечены данные с геологических, тектонических, неотектонических и геоморфологических карт. Возраст поверхностей выравнивания взят в соответствии с картой поверхностей выравнивания.

\section{Результаты исследования}

В результате проведенных исследований была построена карта стадийности развития рельефа Северной Карелии с указанием новейших тектонических структур (рис. 2).

В истории развития рельефа выделяются два этапа пенепленизации и образования обширных поверхностей выравнивания. В первый этап поверхность выравнивания сформировалась в мезозое в условиях длительного денудационного выравнивая на породах архея, протерозоя и палеозоя. Во второй этап образовалась олигоцен-миоценовая поверхность выравнивания (Карта поверхностей..., 1971) на всей территории Северной Карелии, от мезозойской поверхности остались при этом лишь небольшие останцы.

Рис. 2. Карта стадийности развития рельефа Северной Карелии: 1 -поверхности выравнивания мезозойского возраста (250-350 м); 2 - поверхности выравнивания олигоцен-миоценового возраста (150-250 м); 3 - поверхности выравнивания олигоцен-миоценового возраста (100-150 м); 4 - русла рек и ручьев; 5 - граница Беломорского мегаблока и ВедлозерскоСегозерской шовной зоны; 6 - разрывы. Профиль по линии I-I’ показан черной сплошной линией.

Fig. 2. Map of the stages of evolution of the relief of North Karelia: 1 - Mesozoic-age planation surfaces (250-350 M); 2 - Oligocene-Miocene-age planation surfaces $(150-250 \mathrm{~m}) ; 3$ - OligoceneMiocene-age planation surfaces $(100-150 \mathrm{~m})$; 4 - river and stream beds; 5 - boundary of the White Sea megablock and the Vedlozero-Segozero suture zone; 6 - faults. The profile along the line I-I' is shown as a black solid line.

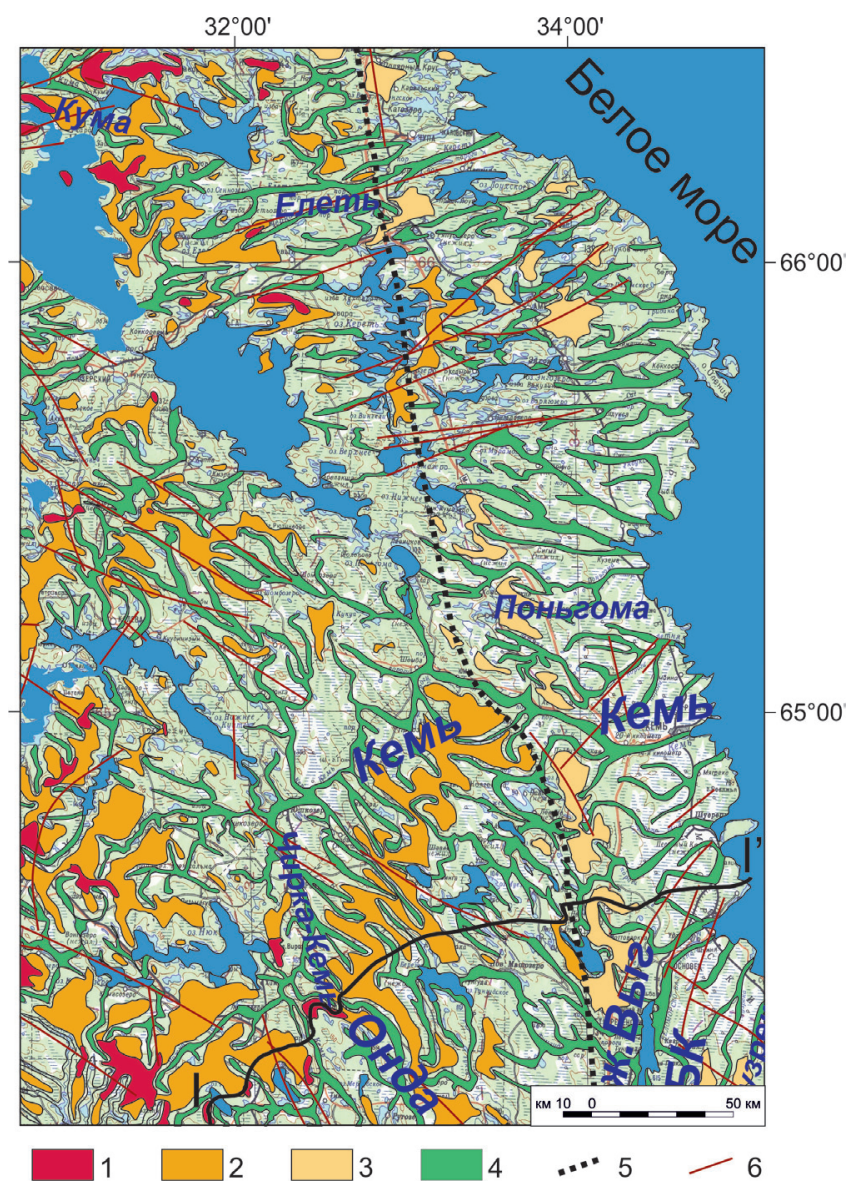

При активизации в новейшее время тектонических движений территория Карелии испытала поднятие, причем в западной и северной частях оно происходило интенсивнее. Об этом говорит, во-первых, наклон всех поверхностей выравнивания на восток (рис. 3), а во-вторых, современные крупные озера (Ср. Куйто, Нюк, Сег-Озеро, Гимольское и др.), расположенные во впадинах рельефа, большей частью представляют собой остатки послеледниковых озер, постепенно уменьшавшихся в своих размерах. И спад воды в них связан с врезанием рек, а также с неравномерным поднятием района. Северо-западные части его в своем поднятии несколько опережают более восточные, с чем связано «сливание» вод к востоку (Геология..., 1960).

Непосредственно на территории исследования выделяются два крупных неотектонических поднятия - Южнокемское и Северокемское (рис. 4). Река Кемь в приустьевой части при этом играет роль границы и вероятно маркирует новейшую отрицательную структуру - Кемско-Топозерский прогиб. 


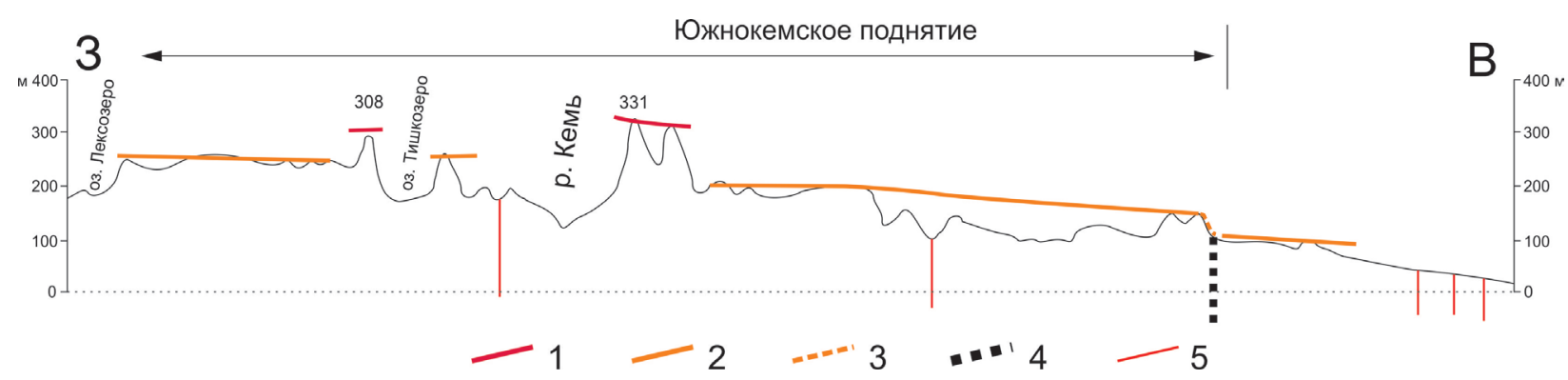

Рис. 3. Структурный профиль рельефа по линии І-І'.

1 - мезозойские поверхности выравнивания; 2 - олигоцен-миоценовые поверхности выравнивания; 3 - ярко выраженная ступень в рельефе; 4 - граница Беломорского мегаблока и Ведлозерско-Сегозерской шовной зоны; 5 - разрывы.

Fig. 3. Structural section of the relief along the line I-I'.

1 - Mesozoic planation surfaces; 2 - Oligocene-Miocene planation surfaces; 3 -a pronounced step in the relief; 4 -the boundary of the White Sea megablock and the Vedlozero-Segozero suture zone; 5 - faults.

В пределах Северокемского поднятия сохранилось большое количество мезозойских поверхностей выравнивания. Олигоценовые поверхности выравнивания развиты в основном в центральной части поднятия. Стоит обратить внимание на рисунок эрозионной сети в восточной части поднятия. Веерообразное расхождение долин рек и ручьев однозначно указывает на развитие новейшего поднятия.

В пределах Южнокемского поднятия мезозойские поверхности сохранились на юго-западе. Олигоценовые поверхности выравнивания также полого наклоняются на восток.

В восточной части обоих поднятий в рельефе наблюдается уступ с изменением высоты поверхностей выравнивания (рис. 4). Этот уступ является границей Беломорского мегаблока и Ведлозерско-Сегозерской межблоковой зоны.

Таким образом, гидротехнические сооружения Кемского каскада ГЭС приурочены либо к границе двух поднятий, либо к Южнокемскому поднятию. Сам КемскоТопозерский прогиб является активной неотектонической структурой. Панасенко Г.Д. (1969) выделил вдоль нее сейсмогенную зону. И действительно, за последние 60 лет непосредственно в пределах этой структуры про-

Рис. 4. Карта новейших структур Северной Карелии: 1 - область новейших поднятий; 2 - область новейшего прогиба; 3-5 - эпицентры землетрясений: 3 - магнитудой $3-4,4$ - магнитудой 2 ; 5 - магнитудой 1-1,5. Профиль по линии I-I’ показан черной сплошной линией.

Fig. 4. Map of the newest structures of North Karelia: 1 - the area of the recent uplifts; 2 - the area of the recent depression; 3-5 - the epicenters of earthquakes: 3 - magnitude 3-4, 4 - magnitude 2; 5 - magnitude 1-1.5. The profile along the line I-I' is shown as a black solid line.

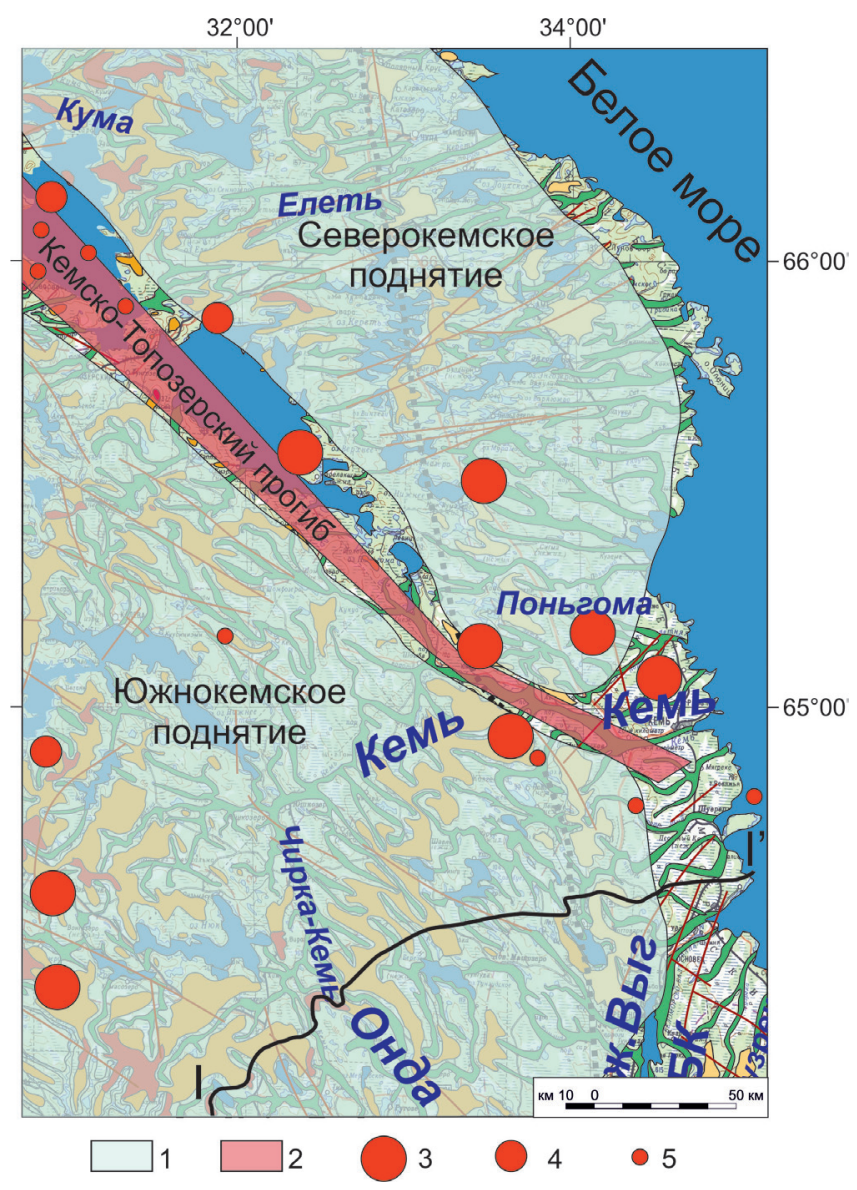


изошло 11 землетрясений с максимальной магнитудой 3.2 (https://www.seismo.helsinki.fi). Активность структуры можно объяснить различием в скоростях развития двух поднятий. Согласно (Лукашов, 1976) в северной части Карелии наблюдается устойчивое умеренное поднятие, тогда как южнее Кемско-Топозерского прогиба выделяется зона дифференцированных движений. Отличие в направлениях новейшего движения возможно и создает напряженную обстановку в этом районе. Ряд землетрясений в районе Костомукши приурочены возможно к другой сейсмогенной зоне, выявить которую пока не удалось.

\section{Выводы}

1. Территория исследования испытывала две стадии пенепленизации - мезозойскую и олигоцен-миоценовую.

2. Образовавшиеся при этом поверхности выравнивания при активизации восходящих тектонических движений испытали наклон в сторону побережья Белого моря, что фиксируется несмотря на сильную расчлененность рельефа.

3. Выделены два новейших поднятия - Северокемское и Южнокемское, разделенные активной сейсмогенной структурой - Кемско-Топозерским прогибом, в пределах которого наблюдается активная сейсмическая обстановка.

4. Большинство гидротехнических сооружений Кемского каскада ГЭС расположены непосредственно в пределах неотектонической и сейсмоактивной структуры на границе двух поднятий. Однако фиксируемая сейсмичность не превышает магнитуды 3. А гидротехнические сооружения повреждаются при магнитуде равной 6-7.

\section{Литература}

1. Геология СССР. Карельская АССР. Т. 37. Ч. 1. Геологическое описание. Ред. Антропов П.Я., Волотовская Н.А., Кратц К.О., Нумерова В.Н. М.: Государственное научно-техническое изд-во литературы по геологии и охране недр, 1960.740 c.

2. Карта поверхностей выравнивания и кор выветривания СССР. Ред. Герасимов И.П., Сидоренко А.В. Масштаб $1: 2500000$. АН СССР, Министерство геологии СССР, 1971 г.

3. Лукашов А.Д. Новейшая тектоника Карелии // АН СССР. Карельский филиал. Институт геологии. Труды. Вып. 31. Л. Изд-во: Наука, 1976. 108 с.

4. Макарова Н.В., Суханова Т.В. Геоморфология. М. Изд-во: КДУ. 2015. 414 с.

5. Панасенко Г.Д. Сейсмические особенности северо-востока Балтийского щита. Л. Изд-во: Наука. 1969. $185 \mathrm{c}$.

6. https://www.seismo.helsinki.fi. 